\title{
Anticancer effects of low-dose 10-hydroxycamptothecin in human colon cancer
}

\author{
YUEH-HSIN PING ${ }^{1 *}$, HSIN-CHEN LEE $^{1 *}$, JEN-YI LEE $^{1}$, PIN-HO WU ${ }^{1}$, LI-KANG HO $^{1}$, \\ CHIN-WEN CHI ${ }^{1,2}$, MING-FONG LU ${ }^{3}$ and JANE-JEN WANG ${ }^{4}$ \\ ${ }^{1}$ Department and Institute of Pharmacology, School of Medicine, National Yang-Ming University; \\ ${ }^{2}$ Department of Medical Research and Education, Taipei Veterans General Hospital; \\ ${ }^{3}$ Targetgen Biotechnology Co.; ${ }^{4}$ National Taipei College of Nursing, Taipei 112, Taiwan
}

Received November 15, 2005; Accepted December 23, 2005

\begin{abstract}
Hydroxycamptothecin (10-HCPT), an indole alkaloid isolated from a Chinese tree, Camptotheca acuminate, inhibits the activity of topoisomerase I and has a broad spectrum of anticancer activity in vitro and in vivo. However, its use has been limited due to its water-insolubility and toxicity with i.v. administration. The purpose of this study was to investigate the efficacy, toxicity and proper dosage of 10-HCPT as a single agent by oral administration in the treatment of human colon cancer. 10-HCPT significantly repressed the proliferation of Colo 205 cells at a relatively low concentration (5-20 nM). Flow cytometry analysis and Western blot and apoptosis assays demonstrated that low-dose 10HCPT arrested Colo 205 cells in the G2 phase of the cell cycle and triggered apoptosis through a caspase-3-dependent pathway. Moreover, following oral administration at doses of 2.5-7.5 mg/kg/2 days, significant suppression of tumor growth by 10 -HCPT was observed in mouse xenografts. No acute toxicity was observed after an oral challenge of 10-HCPT in BALB/c-nude mice every 2 days. The results of this study suggest that a relatively low dose of 10-HCPT (p.o.) is able to inhibit the growth of colon cancer, facilitating the development of a new protocol of human trials with this anticancer drug.
\end{abstract}

\section{Introduction}

Colorectal cancer (CRC) is a major cause of mortality in the Western world (1). For many years, standard chemotherapy for advanced CRC has been based on the thymidylate-synthase inhibitor, 5-FU (2). Although chemotherapy and radiation therapy have been attempted in either adjuvant or palliative

Correspondence to: Dr Jane-Jen Wang, National Taipei College of Nursing, No 365, Ming Te Road, Taipei 11219, Taiwan

E-mail: ccwang@ntcn.edu.tw

${ }^{*}$ Contributed equally

Key words: 10-hydroxycamptothecin, colon cancer, in vivo anticancer, cell cycle arrest, apoptosis treatments, more effective adjuvant therapy is needed for colon cancer patients. Nearly half of all patients with colon cancer die of metastatic disease after curative surgery. Therefore, developing new therapeutic drugs for colon cancer is a worthwhile task.

Camptothecin (CPT), the active component responsible for the anticancer activity in the extract of the plant, Comptotheca acuminate (3), exhibits a broad spectrum of anti-tumor activity against a panel of solid tumors in animal models. Several CPT derivatives (e.g. CPT-11 and TPT) have been introduced into the clinic $(4,5)$. CPT is a TOPO1targeting anticancer drug which shows high $\mathrm{S}$ phase-specific cytotoxicity and induces G2-M cell cycle arrest (6-9). Previous studies showed that a replication fork collision model has been proposed to explain the $\mathrm{S}$ phase cytotoxicity and it is presumably important for the antitumor activity of CPT. 10Hydroxycamptothecin (10-HCPT), another derivative of CPT and a natural alkaloid produced by Camptotheca acuminate, has a wide spectrum of anticancer activity in vitro and in vivo and plays the same significant role in TOPO1-targeting as CPT (10-13). 10-HCPT has an inhibitory effect on phosphorylation of histone $\mathrm{H} 1$ and $\mathrm{H} 3$ in murine hepatoma cells, which may be related to its specific cell killing effect (14), and also exhibits a differentiation inducing effect in human HepG2 cells (15). 10-HCPT, a promising anticancer agent, has undergone clinical trials including the evaluation of different schedules of administration as a single agent and in combination therapy $(16,17)$. Recent clinical studies showed that 10-HCPT was effective on advanced or recurrent solid tumors of NSCLC, CRC and NPC, but myelosuppression was the dose-limiting toxicity and other adverse reactions included nausea, diarrhea and skin rash (17).

The current drugs mainly used for colon cancer treatment are derivatives from CPT (18-20). Although CPT derivatives have been shown to be highly effective in the treatment of colon cancer, the dosage is limited by toxicities (21). In this regard, drug development is needed to improve chemotherapy for patients with locally advanced or metastatic colon carcinoma. Current drug modification is also essential and important for progress. A low-dose long-term strategy has been reconsidered for cancer treatment and oral administration in the clinic appears to be ideal for chemotherapy patients. To better understand how 10-HCPT can be used clinically to orally 
treat patients with cancer, we investigated the preclinical pharmacology of 10-HCPT. We explored the in vivo effects, including the evaluation of different schedules of oral administration, of 10-HCPT in BALB/c-nude mice at different doses using human colon cancer Colo 205 xenografts. Drug administration, dosage and duration were discussed regarding the possibility that 10-HCPT could be a better drug for colon cancer treatment through oral administration. Our results demonstrated that 10-HCPT can be safely orally administered and, alternatively, a low-dose long-term treatment. In addition, molecular studies indicated that the drug could arrest the cell cycle at $\mathrm{S}$ or $\mathrm{G} 2 / \mathrm{M}$ phase depending upon the dosage used. Our results indicated that $10-\mathrm{HCPT}$ significantly reduced the growth of the human colon cell line, both in vitro and in vivo, and has potential as a clinical colon cancer treatment through oral administration.

\section{Materials and methods}

Trypan blue exclusion assay. Colo 205 cells $\left(5 \times 10^{5}\right)$ (ATCC: CCL-222) were seeded in $25 \mathrm{~T}$ flasks overnight and then treated without (control) and with 5, 10, 15 or $20 \mathrm{nM}$ of HCPT, respectively. After treatment for 24-120 h, cells were harvested by trypsin-EDTA and then centrifuged at $1,500 \mathrm{rpm}$ for $5 \mathrm{~min}$ at $4^{\circ} \mathrm{C}$. The cell pellet was resuspended in culture medium containing $0.04 \%$ trypan blue and the viable cells were enumerated by a hemocytometer.

Analysis of cell cycle distribution. After treatment with 10-HCPT, cells were trypsinized and resuspended in $70 \%$ ethanol. The cells were incubated on ice for at least $1 \mathrm{~h}$ and resuspended in $1 \mathrm{ml}$ of cell cycle assay buffer $(0.38 \mathrm{mM}$ sodium citrate, $0.5 \mathrm{mg} / \mathrm{ml}$ RNase A and $0.01 \mathrm{mg} / \mathrm{ml}$ propidium iodide) at a concentration of $5 \times 10^{5}$ cells $/ \mathrm{ml}$. Samples were stored in the dark at $4^{\circ} \mathrm{C}$ until cell cycle analysis, which was carried out by use of a flow cytometer and ModFit LT 2.0 software (Verity Software, Topsham, ME).

Flow cytometry. A FACScan flow cytometer (BectonDickinson, Bedford, MA) equipped with a $488 \mathrm{~nm}$ argon laser was used for analysis of cellular function by flow cytometry. Forward and side scatters were used to establish size gates and exclude cellular debris from the analysis. The excitation wavelength was set at $488 \mathrm{~nm}$. The observation wavelength of $530 \mathrm{~nm}$ was chosen for green fluorescence and $585 \mathrm{~nm}$ for red fluorescence and the intensities of emitted fluorescence were collected on FL1 and FL2 channels, respectively. In each measurement, a minimum of 20,000 cells was analyzed. Data were acquired and analyzed using CellQuest software (BectonDickinson). Relative change in the mean fluorescence intensity was calculated as the ratio between mean fluorescence intensity in the channel of the treated cells and that of the control.

Western blotting. The human colon cancer cell line Colo 205 was cultured in RPMI-1640 supplemented with $10 \%$ fetal bovine serum (FBS) at $37^{\circ} \mathrm{C}$ in a $5 \% \mathrm{CO}_{2}$ atmosphere. Cells were seeded in a 6-well plate and incubated with various concentrations of 10-HCPT. After $48 \mathrm{~h}$, the treated cells were washed twice with phosphate-buffered saline (PBS), flash frozen in liquid nitrogen, and stored at $-80^{\circ} \mathrm{C}$. The harvested cells were lysed in ice-cold report lysis buffer (Promega). After cleaning the resulting lysates by centrifugation, protein in the clear lysate was quantified by Dc Protein Assay Kit (Bio-Rad). Lysate protein $(15 \mu \mathrm{g})$ was resolved by $10 \%$ SDSPAGE, transferred onto a polyvinylidene difluoride membrane (PVDF membrane, Amersham Biosciences), and immunoblotted with antibodies against the following cellular proteins: DNA topoisomerase I, p53, p27, phosphorylated p27 (Santa Cruz Biotechnology), cyclin E, CDK2 (BD Pharmingen), PCNA, p21 (Upstate) and $\alpha$-tubulin (Sigma). The protein content was visualized using a BM chemiluminescence blotting kit (Roche Molecular Biochemicals). The blots were exposed to X-ray film (Fuji) for various times.

Caspase activity assay. N-Acetyl-Asp-Glu-Val-Aps-pNA (DEVD-pNA) cleavage activity was measured using a Caspase-3 colorimetric assay kit (BioVision) according to the recommended protocols. 10-HCPT-treated cells $\left(3 \times 10^{6}\right)$ were harvested, resuspended in $50 \mu 1$ of chilled cell lysis buffer and incubated on ice for $10 \mathrm{~min}$ before centrifugation $\left(12,000 \mathrm{rpm}\right.$ for $3 \mathrm{~min}$ at $\left.4^{\circ} \mathrm{C}\right)$. The supernatant was collected and the total protein concentration of the supernatant was determined using a Dc protein assay kit (Bio-Rad). Each assay reaction containing $100 \mu \mathrm{g}$ of cell lysates, $50 \mu \mathrm{l}$ of $2 \mathrm{X}$ reaction buffer supplemented with $10 \mathrm{mM}$ DTT, and $5 \mu 1$ of the $4 \mathrm{mM}$ of DEVD-pNA ( $200 \mu \mathrm{M}$ final concentration) was carried out at $37^{\circ} \mathrm{C}$ for $1 \mathrm{~h}$. The formation of $p$-nitroanilide was detected at $405 \mathrm{~nm}$ in a microtiter plate reader.

DNA fragmentation. Briefly, treated cells $\left(2 \times 10^{7}\right)$ were centrifuged, and cell pellets were resuspended with NP-40 lysis buffer (1\% NP-40 in $20 \mathrm{mM}$ EDTA and $50 \mathrm{mM}$ Tris- $\mathrm{HCl}$, $\mathrm{pH}$ 7.5). After lysis of cells for a few seconds, the supernatants were collected (5 min at 31,600 g). The extraction was repeated with the same lysis buffer. Sodium dodecyl sulfate at a final concentration of $1 \%$ and RNase at a final concentration of $2.5 \mu \mathrm{g} / \mu \mathrm{l}$ were added to supernatants and incubated for $2 \mathrm{~h}$ at $56^{\circ} \mathrm{C}$. This was followed by digestion with proteinase $\mathrm{K}(2.5 \mu \mathrm{g} / \mu \mathrm{l})$ for $2 \mathrm{~h}$ at $37^{\circ} \mathrm{C}$. Then, the mixtures were brought to $10 \mathrm{M}$ ammonium acetate prior to $100 \%$ ethanol precipitation for $30 \mathrm{~min}$ at $-20^{\circ} \mathrm{C}$. The DNA was collected by centrifugation for $10 \mathrm{~min}$ at $312,000 \mathrm{~g}$ followed by electrophoresis on $1.5 \%$ agarose gel and ethidium bromide staining.

Antitumor activity of 10-HCPT in the BALB/c-nu mouse tumor xenograft model. The in vivo experiment was carried out with ethics committee approval and met the standards required by the Guiding Principles in the Use of Animals in Toxicology, which was adopted by the Society of Toxicology in 1989. BALB/c-nu mice were obtained from the National Laboratory Animal Center of the National Applied Research Laboratories (Taipei, Taiwan) and housed in a laminar flow room under sterilized conditions with a maintained temperature of $25 \pm 2^{\circ} \mathrm{C}$ and a controlled 12-h light and 12-h dark cycle. The Colo 205 cells were harvested and resuspended in serum-free RPMI-1640 medium. Cells were adjusted to $1 \times 10^{7}$ cells $/ \mathrm{ml}$, and transplanted $0.1 \mathrm{ml}$ subcutaneously to the flank regions of the mice. Each experimental group included six to seven mice bearing tumors. 10-HCPT was dissolved in 


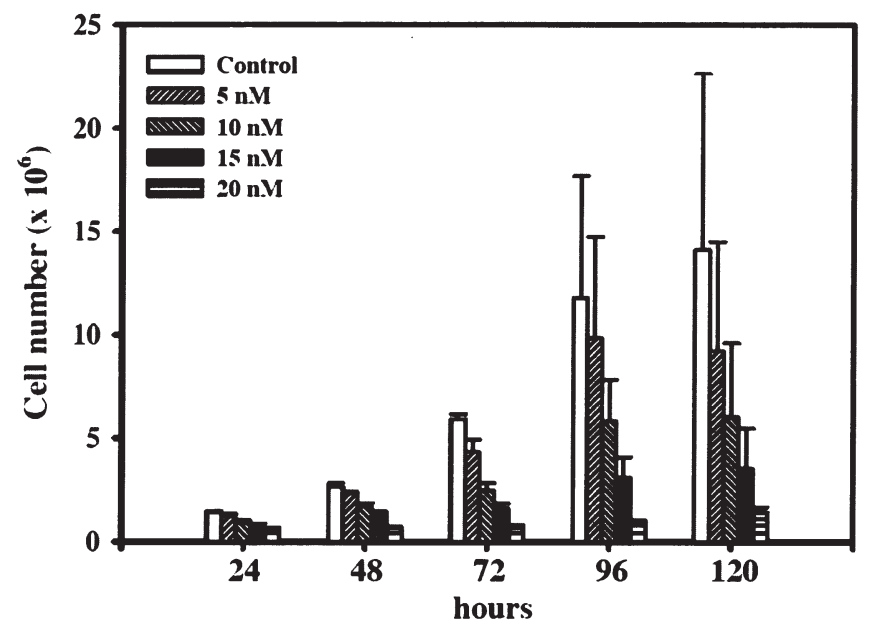

Figure 1. The effect of 10-HCPT on the cell growth of Colo 205. Human colon cancer Colo 205 cells were treated with 5-20 nM of 10-HCPT for different time periods ( $\mathrm{x}$-axis). The viable cell number was counted by trypan blue exclusion assay.

propylene glycol and treatment began when the tumor size reached 3-5 mm. 10-HCPT was administered via p.o. once per two or four days at doses of $1,2.5,5,7.5 \mathrm{mg} / \mathrm{kg}$ (volume of injection: $0.1 \mathrm{ml} / 20 \mathrm{~g}$ of body weight), respectively. The control group received propylene glycol vehicle once per two days. Tumor size and body weight were monitored twice a week throughout the experiment. The tumor size was measured using a vernier caliper. Tumor volume $(\mathrm{V})$ was calculated according to the formula: $\mathrm{V}\left(\mathrm{mm}^{3}\right)=0.4 A B^{2}(22)$, where $A$ and $B$ are the longest diameter and the shortest diameter, respectively. At the end of the experiment, all mice were sacrificed by $\mathrm{CO}_{2}$ gas. Tumors, livers, kidneys and lungs were collected, fixed, embedded and stained with hematoxylin and eosin for pathological analysis.

\section{Results}

10-HCPT inhibits the cell growth and reduces the cell viability of human colon cancer cell line Colo 205. To investigate the effect of 10-HCPT on the growth of the Colo 205 cell line, the cells were treated with a series dosage of 10-HCPT and harvested at different time-points as shown in Fig. 1. The cell numbers were determined by trypan blue exclusion assay. Compared to the untreated cells whose cell number increased with a doubling time of $24 \mathrm{~h}$, the 10-HCPT-treated cells clearly showed a suppression of cell number increase in a dose-dependent manner. When Colo 205 was treated with $20 \mathrm{nM}$ of $10-\mathrm{HCPT}$, the cell number detected at $120 \mathrm{~h}$ was similar to the one measured at $24 \mathrm{~h}$. This result indicates that 10-HCPT suppresses cell growth.

10-HCPT disturbs the cell cycle distribution of human colon cancer cell line Colo 205. We further investigated whether the suppression of cell growth induced by 10-HCPT on Colo 205 was due to either cell cycle arrest or cell death. The Colo 205 cells were treated with various concentrations of 10HCPT for $48 \mathrm{~h}$ and analyzed by propidium iodide staining and flow cytometry (Fig. 2). No significant differences were seen in the $\mathrm{S}$ phase of the cell cycle between untreated and 10-HCPT-treated cells. The treatment of 10-HCPT, however, dramatically induced the increase of cell population in the
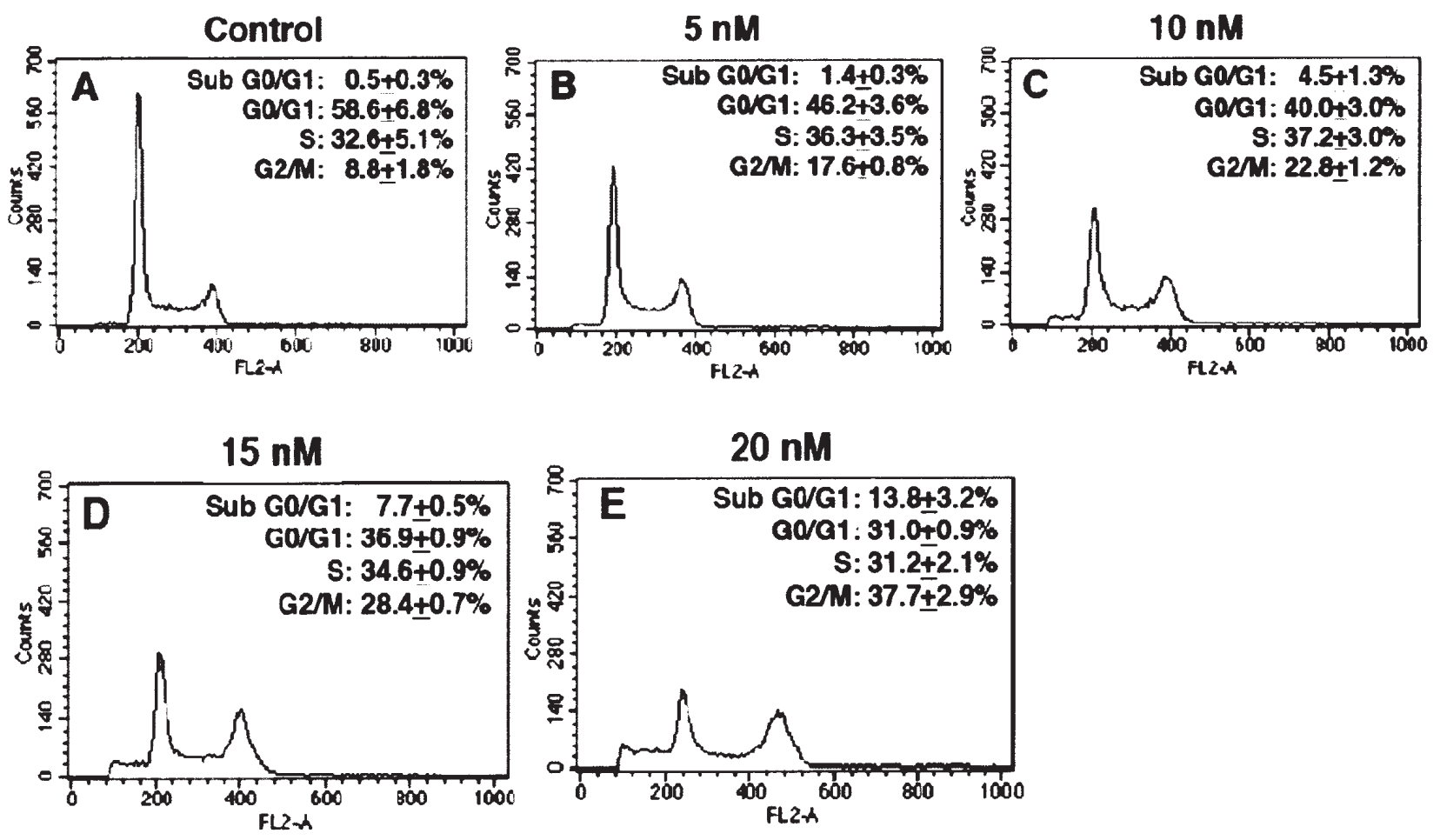

Figure 2. The effect of 10-HCPT on cell cycle distribution of human colon cancer Colo 205 cells. Human colon cancer Colo 205 cells were treated with various concentrations of 10-HCPT, as indicated above each panel, for $48 \mathrm{~h}$. The cell cycle distribution of these cells was analyzed by propidium iodide staining and flow cytometry. 

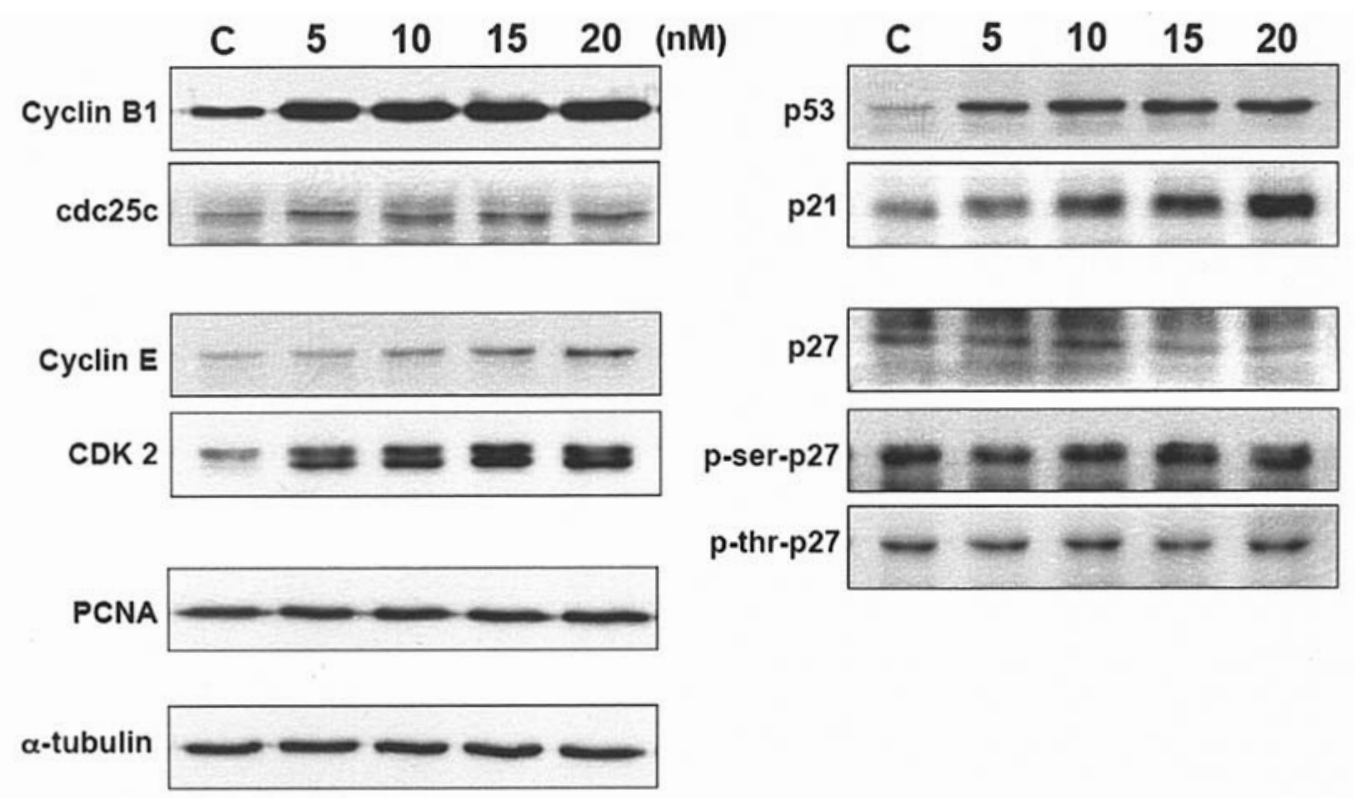

Figure 3. Western blot analysis of cell cycle regulatory proteins. Human colon cancer Colo 205 cells were treated with the various indicated concentrations of 10 -HCPT for $48 \mathrm{~h}$. The expression of regulatory proteins of the cell cycle as well as apoptosis was determined by Western blot assay.

$\mathrm{G} 2 / \mathrm{M}$ phase and a decrease in the G0/G1 phase. This implied that 10-HCPT might cause cell cycle arrest in Colo 205. In addition, flow cytometric analysis also revealed that the increasing population of Colo 205 in sub-G0/G1 phase was induced by $10-\mathrm{HCPT}$. The accumulation of cell numbers in both sub-G0/G1 and G2/M phases was shown in a 10-HCPTtreated dose-dependent manner (Fig. 2F and 2G). These results suggested that the 10-HCPT-induced suppression of cell growth might result from cell cycle arrest as well as apoptosis.

10-HCPT induced cell cycle arrest in the G2/M phase. The progression of the cell cycle is promoted by various CDKs binding with their respective cyclin partners and inhibited by CDK inhibitors such as p21 and p27. In general, CDK2 in association with cyclin $\mathrm{E}$ regulates the G1/S transition, and CDK1 in concert with type-A and $-\mathrm{B}$ cyclins controls the G2/M transition. Both cell cycle inhibitory proteins, p21 and p27, block cell cycle progression at the G1/S as well as the G2/M transitions of the cell cycle. Since 10-HCPT led to an accumulation of cells in the $\mathrm{G} 2 / \mathrm{M}$ phase, we speculated that the underlying molecular mechanism might involve changes in the expression of cell cycle regulatory proteins. To confirm this speculation, we analyzed the expressions of several cell cycle regulatory proteins by means of Western blot assay (Fig. 3). Colo 205 cells were treated with different concentrations of 10-HCPT and harvested at $48 \mathrm{~h}$. The proteins of whole cell lysates were resolved on SDS-PAGE and analyzed by Western blot assay. The increasing expression of cyclin E and CDK2 and the decreasing amount of p27 indicated that 10-HCPT did not affect cells by passing the G1/S check-point and entering the $\mathrm{S}$ phase. The $\mathrm{p} 21$ protein level dramatically increased in a 10-HCPT dose-dependent manner. It resulted in a strong cell cycle $\mathrm{G} 2 / \mathrm{M}$ arrest, although the expression of both cyclin B1 and cdc25c was enhanced by 10-HCPT treatment. In contrast, 10-HCPT showed no effect on PCNA
$\mathbf{A}$

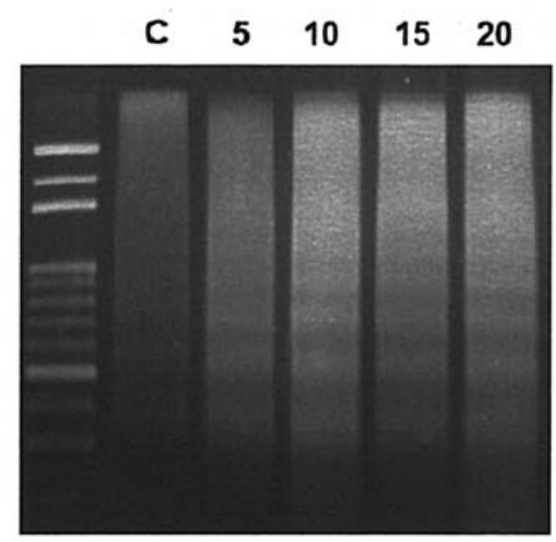

HCPT

(nM)

$48 \mathrm{hrs}$

B



Figure 4. 10-HCPT-induced apoptosis in Colo 205 cells. (A) DNA fragmentation assay. (B) Evaluation of DEVD-dependent cleavage activity by caspase-3. 
(A)
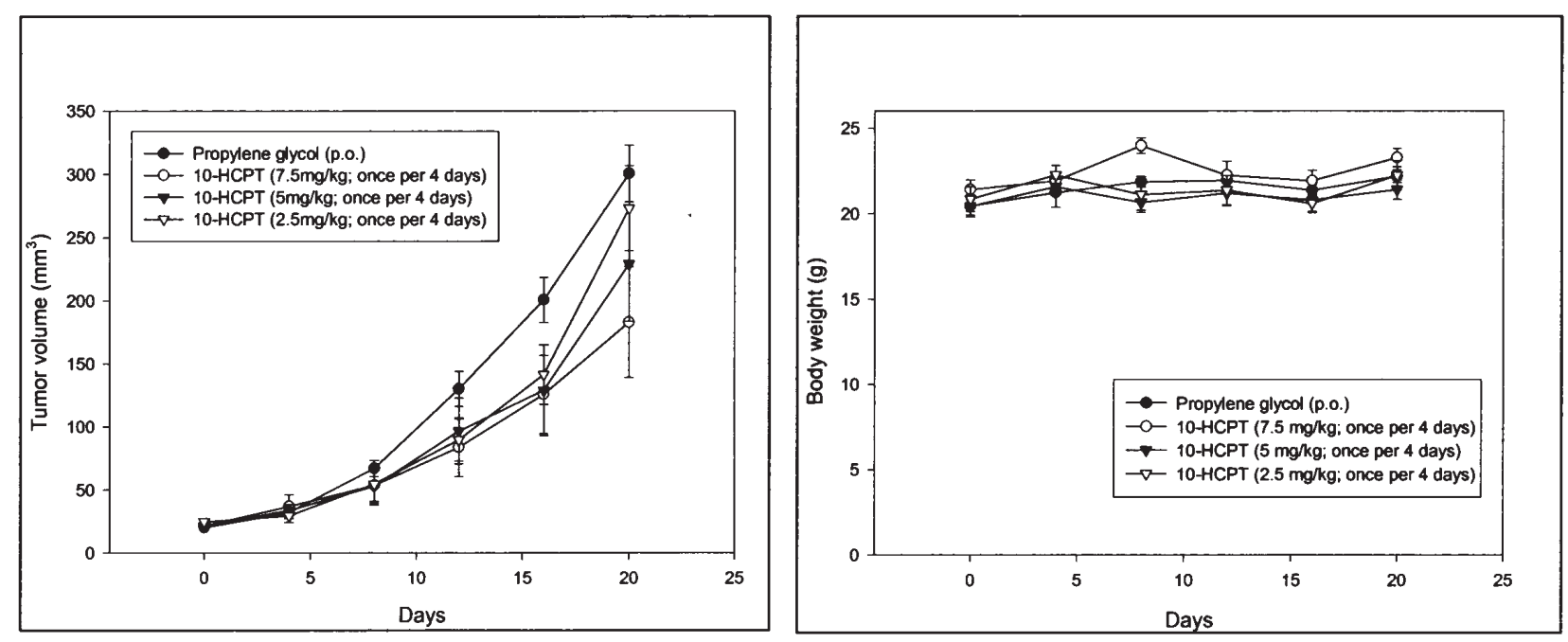

(B)
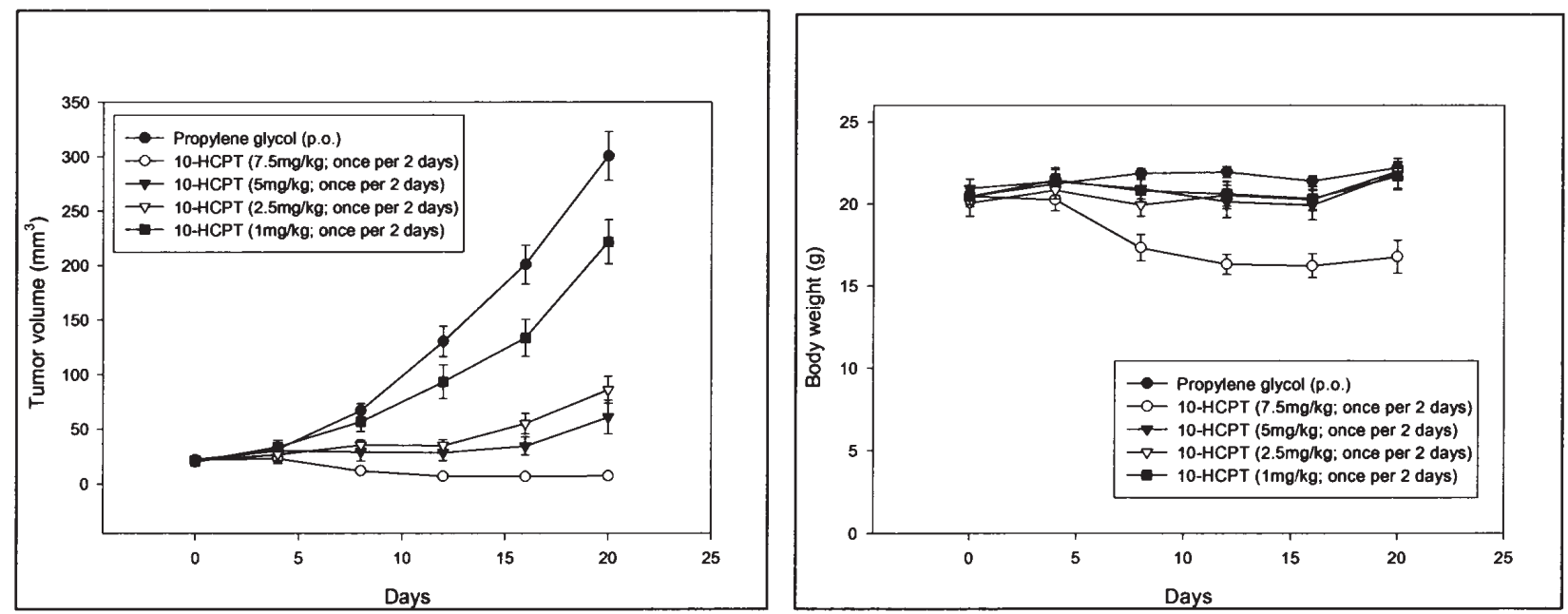

Figure 5. In vivo anticancer effect of 10-HCPT on human colon cancer cell Colo 205 xenografts. When the tumors were palpable (3-5 mm), the BALB/c nude mice were either treated with vehicle control or 10-HCPT (p.o.) every four (A) or two (B) days. Data are the mean \pm SE from 6 to 7 samples of one representative experiment.

protein level. Thus, the dose-dependent expressional changes of $\mathrm{CDK} 2$, cyclin E, cyclin B1, p21 and p27 corresponded with the 10-HCPT-induced effect on cell cycle progression (Figs. 2 and 3).

10-HCPT-induced apoptosis in the Colo 205 cell line. Because apoptosis always takes place as a consequence of cell cycle blockage, it is possible that 10-HCPT is able to cause cell death through apoptosis pathway. To verify this possibility, we first performed DNA fragmentation assay since DNA fragmentation is a character of apoptosis. The DNA of Colo 205 cells treated with various concentration of 10-HCPT for $48 \mathrm{~h}$ was extracted and analyzed by $1.5 \%$ native agarose gel electrophoresis. As shown in Fig. 4A, untreated cells showed no DNA ladders whereas DNA ladders were detected in 10HCPT-treated cells. Increasing the concentration of 10-HCPT resulted in the enhancement of DNA ladders. This result, consistent with the data shown in Fig. 2, suggested that 10HCPT is capable of inducing apoptosis in Colo 205 cells. In addition, to further determine whether caspases participate in the propagation of apoptosis induced by 10-HCPT in Colo 205 cells, cell lysates from drug-treated cells were analyzed for the cleavage of $p$-nitroaniline-tagged peptides DEVD-pNA which represent preferential substrates for caspase-3. Caspase activation leads to the release of pNA that can be monitored by absorbance measurements at $405 \mathrm{~nm}$ using a plate reader. With the DEVD-pNA substrate, the absorbance measured after $10-\mathrm{HCPT}$ treatment of the cells for $48 \mathrm{~h}$ was clearly higher than that measured in the control (drug-free) lysates (Fig. 4B). In contrast, with both IETD-pNA and LEHD-pNA substrates, 10-HCPT only stimulated low caspase activation in Colo 205 cells. These results implied that apoptosis induced by 10-HCPT is through the caspase-3-dependent pathway.

In vivo antiproliferation effect of 10-HCPT for human colon cancer cell Colo 205 xenografts. We further examined whether $10-\mathrm{HCPT}$ is effective in growth suppression in vivo after tumor formation. Colo 205 cells were transplanted into BALB/c-nu mice and, when the tumors were palpable (3-5 mm), the mice were treated either with vehicle control or 10-HCPT (1-7.5 mg/ $\mathrm{kg}$, p.o., once per 2 or 4 days). Fig. 5 showed that the tumor volume from control animals showed an average of $300.5 \pm 22.3 \mathrm{~mm}^{3}$ at the end of this study (day 20). The tumor volume from 10 -HCPT $(2.5,5$ or $7.5 \mathrm{mg} / \mathrm{kg} / 4$ days)-treated 
animals at day 20 had an average of $273.1 \pm 33.7,228.9 \pm 45.3$ and $182.9 \pm 43.9 \mathrm{~mm}^{3}$, respectively (Fig. 5A). The tumor volume was significantly $(\mathrm{p}<0.05)$ decreased in the 5 and $7.5 \mathrm{mg} / \mathrm{kg} /$ 4 days-treated group as compared to the control group at the end of the study. In contrast, the tumor volume from 10-HCPT $(1,2.5,5$ or $7.5 \mathrm{mg} / \mathrm{kg} / 2$ days $)$-treated animals had an average of $221.5 \pm 20.3,85.9 \pm 12.3,60.8 \pm 15.4$ and $7.2 \pm 2.8 \mathrm{~mm}^{3}$, respectively (Fig. 5B). These were significantly $(\mathrm{p}<0.05)$ decreased in mice as compared to control groups at the end of the study.

The challenge of 10-HCPT (1-7.5 mg/kg, p.o., once per 2 or 4 days) in nude mice produced no obvious acute toxicity. No significant reduction in body weight was found in 10-HCPTtreated mice, except for in the $7.5 \mathrm{mg} / \mathrm{kg} / 2$ days-treated group (Fig. 5B). In addition, no tissue damage was observed in the liver, lung and kidney after examination of the tissue slices stained with hematoxylin and eosin (data not shown).

\section{Discussion}

The purpose of the present study was to explore the potential use of low-dose 10-HCPT in the treatment of human colon cancer. We demonstrated that treatment of 10-HCPT, both in vitro and in vivo, is able to repress the growth of colon cancer cells. Moreover, the most important finding of our results is that the anticancer activity of 10-HCPT can be decreased to $\mathrm{nM}$ scale. Following the oral administration of low-dose long-term 10-HCPT, significant anticancer effects and almost remission of human colon cancer xenografts in mice were found. This study may be improve the usage of 10-HCPT in the clinic.

In Colo 205 cells, 10-HCPT significantly repressed the cell proliferation at a relatively low concentration $(5-20 \mathrm{nM})$ compared to previous studies (Fig. 1). The effect of low concentration 10-HCPT was shown in both a dose- and timedependent manner. These results implied the potent antitumor activity of low-dose 10-HCPT clinically. 10-Hydroxycamptothecin (10-HCPT) is the inhibitor of topoisomerase I. Previous studies demonstrated that sensitivity to topoisomerase I poisons is associated with alterations of cell cycle check-point pathways (23). Using flow cytometry analysis, we showed that exposure to various low doses of 10-HCPT, from $5 \mathrm{nM}$ to $20 \mathrm{nM}$, caused an increase in the G2 cell cycle arrest of Colo 205 cells (Fig. 2). Since regulation of the cell cycle is controlled by the activity of $\mathrm{CDK} /$ cyclin complexes, the expression of CDK, cyclin and $\mathrm{CDK}$ inhibitors (CKIs) were examined. Although the expression of cyclin E and CDK2 increased after 10-HCPT treatment, the production of $\mathrm{p} 21$, a CDK inhibitor that may associate with the CDK2/cyclin E complex and inactivate CDK2/cyclin E, was enhanced by 10 -HCPT through the activation of p53 (Fig. 3). Therefore, G2 cell cycle arrest was observed with the administration of low-dose 10-HCPT. In contrast, the decreasing of p27, accompanied by the increased formation of phosphorylated p27 that was targeted by the SCF complex and degraded through the ubiquitination pathway, indicated that Colo 205 cells were capable of passing the G1 check-point (Fig. 3).

In addition, the accumulation of sub-G0/G1 phase cells and DNA fragmentation, both indicating the occurrence of apoptosis, was detected in 10-HCPT-treated Colo 205 cells
(Figs. 2 and 4A). The only known cellular target for 10-HCPT and its analogs is topoisomerase I. These agents trap the topoisomerase I-cleavage complex by inhibiting their religation and, as a consequence, generate DNA damage resulting in apoptosis (24). In mammalian cells, DNA damage leads to the activation of $\mathrm{p} 53$, which stimulates the transcription of a number of genes including CKI proteins and apoptotic proteins (25-28). Our results suggested that low-dose 10-HCPT is able to function as a potent inducer of apoptosis in Colo 205 cells. The induction of apoptosis is associated not only with the change of cell cycle and DNA fragmentation, but also with the activation of caspases. To investigate the signals triggering apoptosis by $10-\mathrm{HCPT}$, caspase activity assay was performed and the results showed that 10-HCPT-induced apoptosis is a caspase-3-dependent pathway (Fig. 4B). However, the activity of caspases 8 and 9 did not increase as much as that of caspase 3 . We, therefore, could not exclude the possibility that caspases 8 and 9 participate in 10-HCPTinduced cytotoxicity, and wonder whether the poisoning of $10-\mathrm{HCPT}$ is through mitochondrial activation. A relatively low dose of 10-HCPT in Colo 205 cells is able to inhibit the growth of cancer cells and trigger apoptosis.

10-Hydroxycamptothecin (10-HCPT) exhibits anticancer activity on several tumor cell lines and xenografts. Previous pharmacokinetic studies indicate that 10 -HCPT has a short distribution half-life and a prolonged elimination half-life, and the dose-dependent toxicity was observed with i.v. administration of 10-HCPT (29). It can be best administered as a loading dose followed by a maintenance dose every other day. Since large amounts of drug were excreted within a short period following i.v. administration, possible side effects on renal function may be observed, especially in the early phase of drug disposition (29). Human colon cancer cells are efficient in drug conjugation catalyzed by UDP-glucuronosyltransferases (UGTs). Regarding the role of glucuronidation in de novo resistance to two topoisomerase I inhibitors, it has been recently shown that drug conjugation catalysed by UDPglucuronosyltransferases (UGTs) functions as an intrinsic mechanism of resistance to the topoisomerase I inhibitors, 7-ethyl-10-hydroxycamptothecin and NU/ICRF 505, in human colon cancer cells (30). Regarding the role of drug transport in this mechanism, increased cellular retention of low-dose CPT occurs (31). As a consequence of more prolonged exposure, enhanced growth inhibitory activity was observed in several human colon cancer cell lines (32). Previous study also suggested that oral administration may be optimal for drug delivery of the water-insoluble CPT analogs (11). Based on these results, the alternative route, oral dosing of 10-HCPT, was used in this study with a low-dose long-term administration strategy. Our results demonstrated tumor growth suppression by 10 -HCPT in nude mouse xenografts following oral administration at a low-dose (Fig. 5). The challenge of 10-HCPT in mice produced no obviously acute toxicity. This result agreed with the in vitro study of Borovitskaya and D'Arpa (32), and in vivo study of Zhang et al (11). We conclude that 10-HCPT can be administered orally and a long-term low maintenance dose of 10-HCPT is the best administration strategy to achieve maximal anticancer effects. The results of this study should be a useful reference for future clinical human colon cancer therapy. 


\section{Acknowledgements}

This study was supported by a grant from Ministry of Economic Affairs (1Z920272), Taiwan. We thank Ms. Shu-Hui Li for excellent technical assistance.

\section{References}

1. Giovannucci E: Modifiable risk factors for colon cancer. Gastroenterol Clin North Am 31: 925-943, 2002.

2. Moertel CG: Chemotherapy for colorectal cancer. N Engl J Med 330: 1136-1142, 1994.

3. Wall ME, Wani MC, Cook CE, Palmer KH, McPhail HT and Sim GA: Plant antitumor agents. I. The isolation and structure of camptothecin, a novel alkaloidal leukemia and tumor inhibitor from camptotheca acuminate. J Am Chem Soc 88: 3888-3890, 1966.

4. Kollmannsberger C, Mross K, Jakob A, Kanz L and Bokemeyer C: Topotecan - a novel topoisomerase I inhibitor: Pharmacology and clinical experience. Oncology 56: 1-12, 1999.

5. Rosen LS: Irinotecan in lymphoma, leukemia, and breast, pancreatic, ovarian, and small-cell lung cancers. Oncology 12: 103-109, 1998.

6. Gallo RC, Whang-Peng J and Adamson RH: Studies on the antitumor activity, mechanism of action, and cell cycle effects of camptothecin. J Natl Cancer Inst 46: 789-795, 1971.

7. Horwitz MS and Horwitz SB: Intracellular degradation of HeLa and adenovirus type 2 DNA induced by camptothecin. Biochem Biophys Res Commun 45: 723-727, 1971.

8. Horwitz SB, Chang CK and Grollman AP: Studies on camptothecin. I. Effects of nucleic acid and protein synthesis. Mol Pharmacol 7: 632-644, 1971.

9. Kessel D, Bosmann HB and Lohr K: Camptothecin effects on DNA synthesis in murine leukemia cells. Biochim Biophys Acta 269: 210-216, 1972.

10. Ling YH, Andersson BS and Nelson JA: DNA topoisomerase I as a site of action for 10-hydroxycamptothecin in human promyelocytic leukemia cells. Cancer Biochem Biophys 11: 23-30, 1990.

11. Zhang R, Cai Q, Lindsey JR, Li Y, Chambless B and Naguib FNM: Antitumor activity and pharmacokinetics following oral administration of natural product DNA topoisomerase I inhibitors 10-hydroxycamptothecin and camptothecin in SCID mice bearing human breast cancer xenografts. Int J Oncol 10: 1147-1156, 1997.

12. Liang YJ, Fu LW, Ding Y, Xiong HY, Chen LM, Yang XP and Pan QC: Experimental studies on treatment of nasopharyngeal carcinoma with combination regimen of hydroxycamptothecin and etoposide. Aizheng 22: 368-371, 2003.

13. Zhou JJ, Liu J and Xu B: Relationship between lactone ring forms of HCPT and their antitumor activities. Acta Pharmacol Sinica 22: 827-830, 2001.

14. Ling $\mathrm{YH}$ and $\mathrm{Xu} \mathrm{B}$ : Inhibition of phosphorylation of histone $\mathrm{H} 1$ and $\mathrm{H} 3$ induced by 10-hydroxycamptothecin, DNA topoisomerase I inhibitor, in murine ascites hepatoma cells. Zhongguo Yao Li Xue Bao 14: 546-550, 1993.

15. Zhang X, Zhou Y and Xu B: Differentiation of human hepatoma Hep G2 cells induced by 10-hydroxycamptothecin. Chin Med J (Engl) 113: 712-713, 2000.
16. Han R: Highlight on the studies of anticancer drugs derived from plants in China. Stem Cells 12: 53-63, 1994.

17. Huang HQ, Jiang WQ, Hu XH, Lin XB, Liu KF, Li YH, Lin Z, Shen WX, Chen Q, He YJ and Guan ZZ: Preliminary study of lyophilized 10-hydroxycamptothecin in advanced or recurrent malignancies. Aizheng 22: 1334-1338, 2003.

18. O'Leary J and Muggia FM: Camptothecins: A review of their development and schedules of administration. Eur J Cancer 34: 1500-1508, 1998.

19. Takimoto $\mathrm{CH}$, Wright $\mathrm{J}$ and Arbuck SG: Clinical applications of the camptothecins. Biochim Biophys Acta 1400: 107-119, 1998.

20. Saitz LB, Cox JV, Blanke C, Rosen LS, Fehrenbacher L, Moore MJ, Maroun JA, Ackland SP, Locker PK, Pirotta N, Elfring GL and Miller LL: Irinotecan plus fluorouracil and leucovorin for metastatic colorectal cancer. Irinotecan Study Group. N Engl J Med 343: 905-914, 2000.

21. Hecht JR: Gastrointestinal toxicity of irinotecan. Oncology (Huntingt) 12: 72-78, 1998.

22. Attia MA and Weiss DW: Immunology of spontaneous mammary carcinomas in mice. V. Acquired tumor resistance and enhancement in strain A mice infected with mammary tumor virus. Cancer Res 26: 1787-1800, 1966

23. Yin MB, Hapke G, Guo B, Azrak RG, Frank C and Rustum YM: The Chk1-Cdc25C regulation is involved in sensitizing A253 cells to a novel topoisomerase I inhibitor BNP1350 by bax gene transfer. Oncogene 20: 5249-5257, 2001.

24. Tsao YP, Russo A, Nyamuswa G, Silber R and Liu LF: Interaction between replication forks and topoisomerase I-DNA cleavable complexes: studies in a cell-free SV40 DNA replication system. Cancer Res 53: 5908-5914, 1993.

25. Appella E and Anderson CW: Post-translational modifications and activation of p53 by genotoxic stresses. Eur J Biochem 268: 2764-2772, 2001

26. Benchimol S: p53-dependent pathways of apoptosis. Cell Death Differ 8: 1049-1051, 2001.

27. Giaccia AJ and Kastan MB: The complexity of p53 modulation: emerging patterns from divergent signals. Genes Dev 12: 2973-2983, 1998

28. Yu J, Wang Z, Kinzler KW, Vogelstein B and Zhang L: PUMA mediates the apoptotic response to p53 in colorectal cancer cells. Proc Natl Acad Sci USA 100: 1931-1936, 2003.

29. Zhang R, Li Y, Cai Q, Liu T, Sun H and Chambless B: Preclinical pharmacology of the natural product anticancer agent 10-hydroxycamptothecin, an inhibitor of topoisomerase I. Cancer Chemother Pharmacol 41: 257-267, 1998

30. Cummings J, Ethell BT, Jardine L, Boyd G, Macpherson JS, Burchell B, Smyth JF and Jodrell DI: Glucuronidation as a mechanism of intrinsic drug resistance in human colon cancer: reversal of resistance by food additives. Cancer Res 63: 8443-8450, 2003.

31. Cummings J, Zelcer N, Allen JD, Yao D, Boyd G, Maliepaard M, Friedberg TH, Smyth JF and Jodrell DI: Glucuronidation as a mechanism of intrinsic drug resistance in colon cancer cells: contribution of drug transport proteins. Biochem Pharmacol 67: 31-39, 2004

32. Borovitskaya AE and D'Arpa P: Replication-dependent and independent camptothecin cytotoxicity of seven human colon tumor cell lines. Oncol Res 10: 271-276, 1998. 